\title{
Effects of Information Security Management Systems on Firm Performance
}

\author{
Harold Nguegang Tewamba ${ }^{1}$, Jean Robert Kala Kamdjoug', Georges Bell Bitjoka ${ }^{2}$, , \\ Samuel Fosso Wamba ${ }^{3}$, Nicolas Nkondock Mi Bahanag ${ }^{4}$ \\ ${ }^{1}$ FSSG, Catholic University of Central Africa, Yaounde, Cameroon \\ ${ }^{2}$ Department of Telecommunications, National Advanced School of Engineering of the University of Yde1, Yaoundé, Cameroon \\ ${ }^{3}$ Department of Information, Operations and Decision Sciences, Toulouse Business School, Toulouse, France \\ ${ }^{4}$ Department of Computer Science, University of Yaounde I, Yaounde, Cameroun \\ Email address: \\ haroldnguegang@gmail.com (H. N. Tewamba), jrkala@gmail.com (J. R. K. Kamdjoug), georges@bellbitjoka.com (G. B. Bitjoka), \\ fossowam@gmail.com (S. F. Wamba), nicolas.nkondock@gmail.com (N. N. Mi Bahanag) \\ ${ }^{*}$ Corresponding author
}

\section{To cite this article:}

Harold NguegangTewamba, Jean Robert Kala Kamdjoug, Georges Bell Bitjoka, Samuel FossoWamba, Nicolas Nkondock Mi Bahanag. Effects of Information Security Management Systems on Firm Performance. American Journal of Operations Management and Information Systems. Vol. 4, No. 3, 2019, pp. 99-108. doi: 10.11648/j.ajomis.20190403.15

Received: August 10, 2019; Accepted: September 18, 2019; Published: September 29, 2019

\begin{abstract}
The purpose of this paper is to determine the aspects of the information security management system (ISMS) on which decision-makers must act to achieve the performance targets. Information assets as core of any Information systems (IS) should be taken seriously by a custom security. In this research, we conduct a case study specially using the Delone and McLean's IS success model. The hypotheses were tested by PLS-SEM of theSmartPLS software using survey data collected among 136 IS and IT professionals. We found that the ISMS (system, service and information qualities, maturity level of information security risk management process) and performance are directly related on one hand, and indirectly by the IT capabilities of the company in the other hand. This shows that mastering security information management risks process is crucial for an enterprise because it greatly contributes to organizational performance, improve the IS' support such as IT management, IT personal skills and IT infrastructure. This work has explored the feasibility of using the IS success model on ISMS, a key world know element, where Africa is both the target of the informational mobility, hackers and especially in the global economy. We consider the IS success model with 4 dependent variables including maturity level of process.
\end{abstract}

Keywords: IS Success Model, ISMS, Maturity Level, IT Capability, Firm Performance

\section{Introduction}

Today, the adoption of information technology (IT) has become a necessity for all organizations. IT are made of resources and processes, with a strong influence on security and performance. They allow rapid processing of information used daily by companies to achieve their goals, to meet the needs of stakeholders and to adapt to their environment.

In the management process and external environment of a company, many types of information flow. These information is necessary for the achievement of objectives on one hand and expose enterprises to many risks on the other hand [1]. Thus, this information must be confidential, honest and available [2]. The information security management system (ISMS) stand guarantor for information security in a company. This is the part of the overall management system, based on a risk business approach, to establish, implement, operate, monitor, review, maintain and improve the information security. The presence of an ISMS in an organization, according to the same reference, emphasizes on a regular IT risk management based on the security objectives in other to measure the level of information security related to assets to protect, to security measures 
implemented and to potential threats.

The protection of the informational resources is a fundamental responsibility of the corporate governance [3]. The ISMS is so far important. It protects the information assets against threats that may affect its operation. It must be reactive and be able to adapt rapidly, in this changing environment.

However, the adoption of the informational mobility and the rise of cybercrime expose companies to the greater informational risk whose non-inclusion in daily activities may result in serious consequences to a corporate crisis. These consequences are likely to reduce the image and operational performance of the company.

In the availability care of their services, telecom company for example get a second connection for emergency. This connection called backup. It generally not as robust as the principal connection. It permits to guarantee interconnection between infrastructure in case of weakness of the principal connection in order to permit availability $24 / 24$ and $7 / 7$ of their network. Therefore, maintaining customer satisfaction at the high level further. After adoption of a backup, it will be make choice on the quality of backup in order to maintain key performance indicators at the satisfaction threshold fixed by organization. This choice depends on the quality of the personnel skills.

An observation made on the procurement department of a great public works company allowed us to note a significant number of incidents due to improper prescription of products to supply. Products ordered did not meet the technical requirements mentioned on the order form or required by the technician. This situation may result in an increase of delivery costs for the supplier or a delay of delivery and execution of works for the enterprise. If the security guarantees the information integrity, then it should be able to solve this problem on this company.

We can therefore ask how the improvement of the ISMS provides the improvement of the performance in a company?

The aim of our research is to demonstrate that the information security management is a source of performance within a company. This will allow the adoption of a serious and rigorous IS management system by any enterprise in our environment. The information systems security (ISS) doesn't appear as a center costs. Companies can now invest in the security of their IS so as to create more value.

To answer our research question, we developed a research model and tested our hypotheses and the different mediation effects. We first of all explored previous studies and then analyzed related theories in order to propose our research model. Thereafter, we presented our methodology and results, and finally we discussed the results and presented the various implications of our work.

\section{Theoretical Background}

\subsection{Theoretic Models}

The first Delone and McLean [4] IS success model aimed to provide a general definition and a measurement model of successful IS. After various criticisms of several researchers like Pitt et al. in [5] who recommend that service quality should be added as a dependent variable, Delone and McLeandecide to revise their model ten years after. So, they proposed an improved model with six (06) variables which is a framework for measuring dependent variables that get results about the success and quality of an IS. These variables are the following: system quality, Information quality, Service quality, Use of the system / intention to use, User satisfaction and Net benefits. In this new model, they consider "net benefits" like the combination of "individual impact" and "organizational impact".

The IS success model sustained that a system can be assessed based on the quality of the information provided and the delivered services, and the characteristics of the system itself. These factors affect users (satisfaction and intention to use). After using the system, it will derive benefits for the user and therefore for the organization. These benefits in return motivate more users.

The service quality variable is a model himself; the SERVQUAL. It is an instrument used to measure the service quality of acompany. According to the authors, quality of service is measured by observing the difference between the perceived service quality and the expected by the customer [6]. If this difference is positive, then its follow that the quality of service is good and service does not need instant improvement. If the difference is negative, then its follow that the quality of service is not good and the service need improvement.

SERVQUAL has five (05) measurement indicators: Tangibles, Reliability, Responsiveness, Assurance and Empathy. As far as it is a framework for any enterprise, there is a possibility to make a self-evaluation of the service. This also allows internal continuous improvement of service quality.

Resource-based theory was developed to sustain that a company that has resources is able to have a competitive advantage that can be maintained for a long term in order to be performant. This advantage can be maintained because any company is able to protect itself against skills and technology transfer or imitation [7]. Authors sustain that IT resources are necessary but not sufficient for good firm performance. Similarly, only acquire IT resources does not ensure good corporate performance. They define resources as any skills and abilities, strategic property, assets or capabilities used to meet the market's opportunities and threats. Assets are tangibles (network infrastructure, workstation, etc.) and intangibles (software, relationship with stakeholders, etc.) [8]. The capability is the means which allows to use these assets to achieve goals; such as technical and managerial skills [9]. The resource-based theory allows us to easily specify the resources of a company, to easily establish the link between resources and competitive advantage, so to measure resource benefits. This enable a comparison between company.

Regarding the resource-based theory, it appears that 
resources are static while our environment is dynamic. Taking into consideration that a company must always fit one's surroundings, raised the theory of dynamic capability. This theory sustain that resources should be developed and integrated within a company. In [10], one of the pioneer of this theory, define the dynamic capacity as the ability to integrate, build and reconfigure internal and external skills to adapt to rapid environment changings. As such, the dynamic capacity theory fills the gap dynamically with a process orientation between resources and the environment [11]. We can say that the resource-based theory facilitates the choice of resources while the dynamic capability enables the development and renewal of these resources.

\subsection{Research Model}

A successful company is both effective and efficient. The firm performance can be measured at several levels: financial, social, administrative, marketing, etc.

In our environment, at this numeric era where information security is indispensable like entire activity, many company don't take aware of their information values when this information are a company assets and permit all days to accomplish their purposes and be performant. In addition, some authors say that Delone and McLean IS success model may be apply to many sub-system types of an IS in $[12,13]$ by Gorla et al. Thus, we propose to use Delone and McLean IS success model to verify if ISMS in a company permit to be performant.

The IS success model was subject of several scientific articles. Some authors used the original model [14-17]. Others determined the factors of satisfaction and usage [18, 19]. While others used it without consideration of some variables such as user satisfaction, use and individual impact in [20] and by Gorla et al.

We focused on the model used by Gorla et al. Their goal was to measure the direct effect of IS (system quality, service quality and information quality) on administrative and marketing performance. This interests us because the management through business process is important [21]. The relationship with suppliers is not always taken into account whereas they participate in achieving business goals. In addition, the customer should always be satisfied and because one of the strengths of a company is its image [22]. Gorla et al. conclude that IS have a positive effect on a firm performance. We can think one or all parts of IS have a positive effect on a firm performance.

Given that risk management is a major and inevitable activity of all ISMS [23], we propose to assessthe maturity of risk management process (RM-CMM) according to ISO 27005 , each in its entirety.

Regarding this observations, we can formulate the first hypothesis H1: ISMS has a positive effect on a firm performance.

The information security risk management process permit company to improve efficacy and efficiency of there is, therefore to improve their IT. The risk management tools like MEHARI, EBIOS, propose recommendations on the improvement of IT capabilities (infrastructure, application, management, personnel skills, etc.). As the risk management is an important activity of ISMS, we can formulate de second hypothesis H2: ISMS has a positive effect on the IT capabilities.

Bharadwaj et al state that IT capabilities have a positive effect on the firm performance; on the firm organizational performance [24]; on the firm marketing performance [25]. Bharadwaj et al distinguish IT tangible resources (infrastructure, human resources) and IT intangible resources (knowledge). Our research paper turn attention to tangibles resources to avoid abstract elements like personnel skills, knowledge capability which are intangibles. Then, we can formulate third hypothesis H3: IT capabilities have a positive effect on firm performance.

Thus, our research model (Figure 1) is presented below.

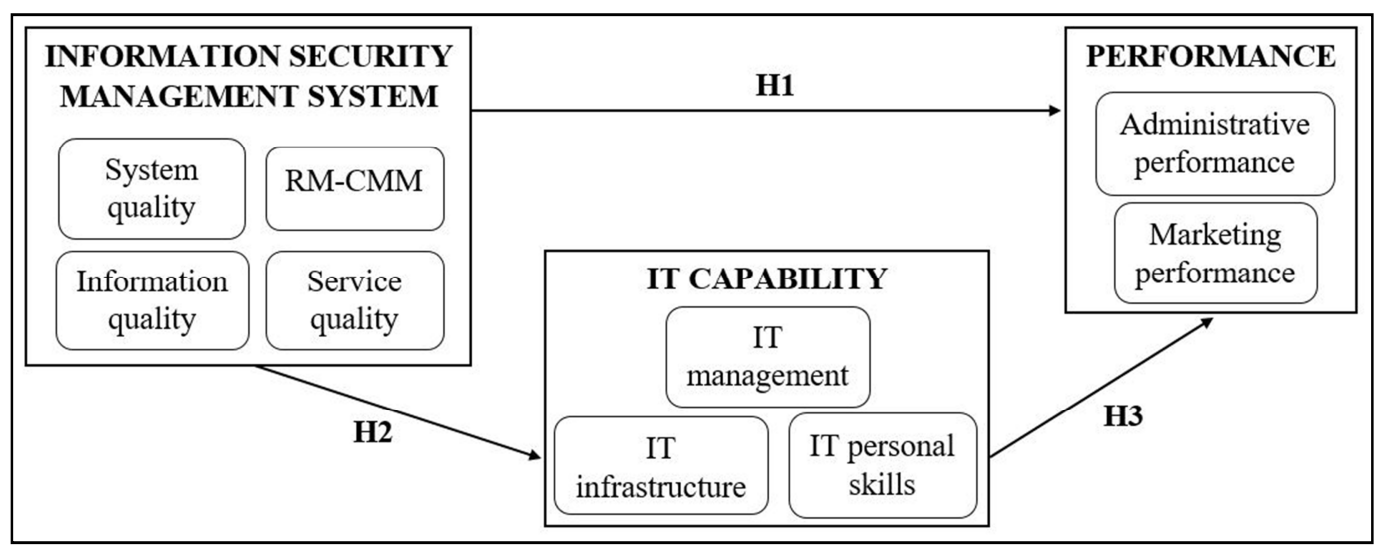

Figure 1. Research model.

The use of these cited different theories and concepts offer us opportunities for accurate and detailed verification of our research model with some dependent relations. Gorla et al say it is possible to explore the effects between system, service and information quality. Thus, we obtain the specific research model below. This specific research model adds 11 research hypotheses to our paper. 


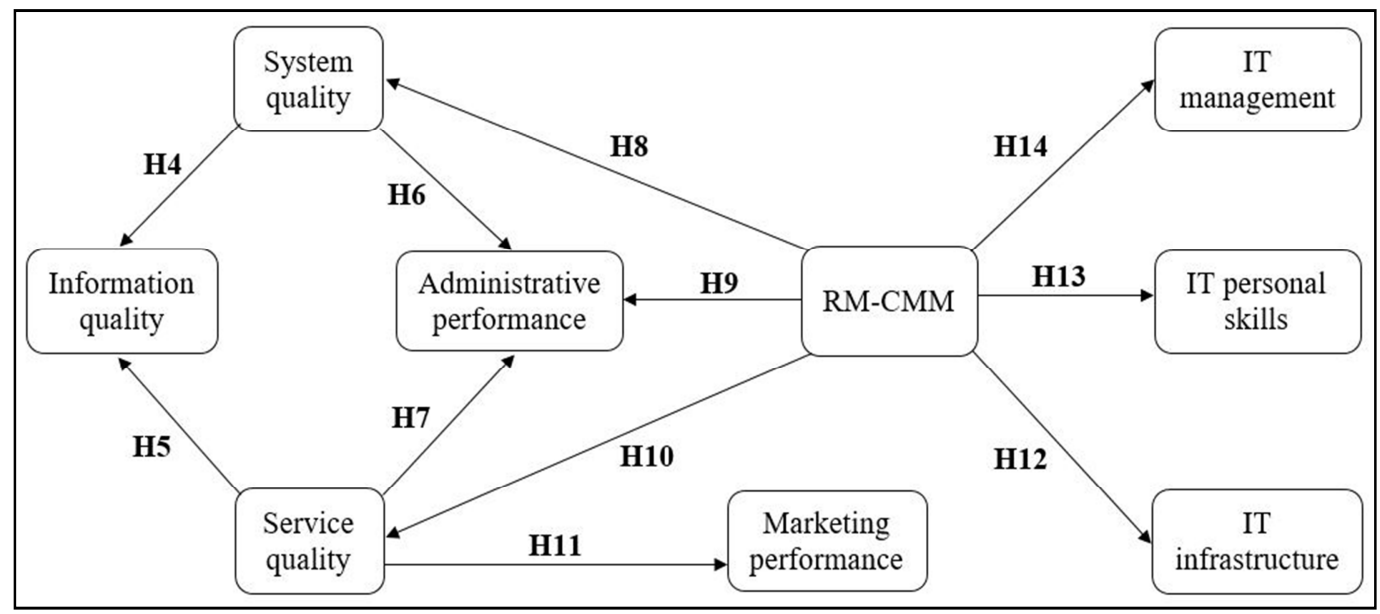

Figure 2. Specific research model.

\section{Methodology}

To verify our different hypotheses, we will use a hypothetical-deductive approach using quantitative data collected with a survey [26]. The hypothetical deductive approach has proven itself in the field of social sciences through the method of structural equation modeling (SEM), the partial least square (PLS) and combined. The PLS method has successfully treated the models and theories using in development of our research model.

Our sample was made for IT, security and IS professionals and managers in enterprises. Our survey, with 41 questions, structured into two parts: thirty-five (35) questions using a 7pointsLikert scale and six (06) using a 5-pointsLikert scale measuring maturity level. Among the 485 online questionnaires sent, 136 have been collected. The minimum sample size for hypothesis testing is obtained by multiplying the highest number of manifest variables by10 [27]. In our research model, the latent variable that has the most manifest variable is Administrative performance. It has nine (09) indicators. Therefore, the minimum sample size is ninety (90) observations.

Data analysis is done using Smart PLS software. Firstly, we realized the quality analysis of our different constructs using Outer loadings, Discriminant validity in [28], Composite reliability and Alpha Cronbach in [29], AVE by Hair et al, and HTMT criterion by Henseler et al. Secondly, we tested the significance of each relations as to confirm different hypotheses. Thus, we will apply the Smart PLS bootstrapping method with 5000 bootstrap samples as recommended by Hair et al. The significance indicator is the Student t-statistic. Finally, we will analyze the existing mediation effects between constructs in order to address the nature of certain dependent relationships [30-33].

\section{Results}

\subsection{Characteristics of Respondents}

We received 136 questionnaires from a population whose characteristics are:

According to the activity, $32 \%$ are for services, $21 \%$ for telecommunications, $18 \%$ for consultants and $10 \%$ for bank, $5 \%$ for e-commerce, $4 \%$ for insurance, $4 \%$ for transport and logistics, $2 \%$ for the work public, $1 \%$ for the industry and $4 \%$ for others;

$49 \%$ worked in a large company, $16 \%$ in medium enterprises, $20 \%$ in small business and $15 \%$ in very small businesses.

$84 \%$ of respondents are male and $16 \%$ female.

$60 \%$ of respondents are managers, $22 \%$ are officers and $18 \%$ are top managers.

$55 \%$ of respondents have received information security training (seminars, certification) against $45 \%$.

\subsection{Results of the Research Model}

External model analysis concern the characteristics of our constructs. Results are given in the following table.

Table 1. Characteristics of constructs.

\begin{tabular}{|c|c|c|c|c|c|c|}
\hline Constructs & Number of indicators & Average & Ecart types & Cronbach's alpha & Composite reliability (CR) & $(A V E)$ \\
\hline ISMS & 20 & 4,452 & 1,573 & 0,962 & 0,966 & 0,586 \\
\hline IT Capacity & 10 & 5,375 & 1,570 & 0,932 & 0,943 & 0,625 \\
\hline Performance & 11 & 4,810 & 1,583 & 0,960 & 0,965 & 0,715 \\
\hline
\end{tabular}

According to the different authors mentioned in respective references, the values of Cronbach's alpha and composite reliability (CR) are above 0.7 . The values of AVE are above 0.5. Therefore, our constructs are reliable and have a good internal consistency and convergent validity.
Global analysis of the research model regarding the quality of our model is tested using the HTMT criterion. It measures the discriminant validity of the constructs. This criterion is more appropriate than the Fornell-Larcker's criterion and cross-loadings analysis. 
Table 2. Indicators of HTMT criterion.

\begin{tabular}{ll}
\hline & HTMT \\
\hline Performance- IT Capacity & 0,697 \\
ISMS & 0,633 \\
ISMS & 0,825 \\
\hline
\end{tabular}

Table 2 shows the values of HTMT below 0.85 . This result signifies that a construct is not explained by on or others. To have more insight of the predicative power of the model, we also analyzed the value of $\mathrm{R}^{2}$. It is the proportion of the variability of the dependent variable explained by its independent variables. We had 0.391 for the IT CAPABILITY for 0.702 for PERFORMANCE. We conclude that this model has a good discriminant validity and is generally interesting.

Concerning internal model analysis, the table 3 shows the value of the Student statistic (t) are greater than 1.96; explaining the existence of a strong link between our constructs. Moreover, the error probability of the links between our constructs is very low. Therefore, all our hypotheses are accepted.

Table 3. Test results of our hypotheses.

\begin{tabular}{lllll}
\hline & Hypotheses & Coefficient & t & p \\
\hline H1 & ISMS $\rightarrow$ Performance & 0,621 & 11,972 & 0,000 \\
H2 & ISMS $\rightarrow$ IT Capacity & 0,625 & 7,665 & 0,000 \\
H3 & IT Capacity $\rightarrow$ Performance & 0,295 & 5,389 & 0,000 \\
\hline
\end{tabular}

According to the mediation effect analysis process proposed by Nitzl et al., we note that the direct and indirect effect between the ISMS and PERFORMANCE are significant (see Table 4) because the value of the t-statistic for each link is greater than 1.96 by Hair et al., This means that the IT CAPABILITY has a partial significant mediation effect between ISMS and PERFORMANCE. This result was also confirmed with the testsof Baron and Kenny and Sobel.

Table 4. Test results of the mediation effects.

\begin{tabular}{llll}
\hline Tests & Links & Coefficients & t \\
\hline Indirect effect & ISMS $\rightarrow$ IT Capacity $\rightarrow$ Performance & 0,184 & 4,076 \\
direct effect & ISMS $\rightarrow$ Performance & 0,621 & 0,000 \\
\hline
\end{tabular}

Table 5 shows averages and standard deviations of items for each sub-construct. The average of an item represents the main response given by observations. The standard deviation is the distribution of observations following an item in [34].

Table 5. Descriptive characteristics of sub constructs

\begin{tabular}{|c|c|c|c|c|}
\hline Constructs & Sub-constructs & Items & Average & Ecart-types \\
\hline \multirow{18}{*}{ SMSI } & \multirow{6}{*}{ RM-CMM } & RM1 & 3,324 & 1,194 \\
\hline & & RM2 & 3,434 & 1,168 \\
\hline & & RM3 & 3,5 & 1,05 \\
\hline & & RM4 & 3,382 & 1,118 \\
\hline & & RM5 & 3,522 & 1,157 \\
\hline & & RM6 & 3,324 & 1,212 \\
\hline & \multirow{5}{*}{ SYSQUAL } & SYQ2 & 5,147 & 1,348 \\
\hline & & SYQ3 & 4,676 & 1,46 \\
\hline & & SYQ4 & 4,471 & 1,317 \\
\hline & & SYQ5 & 4,632 & 1,366 \\
\hline & & SYQ6 & 4,375 & 1,548 \\
\hline & \multirow{2}{*}{ INFOQUAL } & INQ1 & 5,309 & 1,303 \\
\hline & & INQ3 & 4,779 & 1,012 \\
\hline & \multirow{5}{*}{ SERVQUAL } & SEQ1 & 5,206 & 1,301 \\
\hline & & SEQ2 & 4,551 & 1,599 \\
\hline & & SEQ3 & 4,868 & 1,519 \\
\hline & & SEQ4 & 5,007 & 1,417 \\
\hline & & SEQ5 & 5,11 & 1,464 \\
\hline \multirow{7}{*}{ IT CAPACITY } & \multirow{4}{*}{ IT-INFRASTRUCTURE } & IIT1 & 5,713 & 1,266 \\
\hline & & IIT2 & 5,456 & 1,339 \\
\hline & & IIT3 & 5,831 & 1,252 \\
\hline & & IIT4 & 5,301 & 1,804 \\
\hline & \multirow{2}{*}{ IT-PERSONNEL } & PIT1 & 5,037 & 1,602 \\
\hline & & PIT2 & 5,618 & 1,231 \\
\hline & IT-MANAGEMENT & MIT1 & 5,015 & 1,671 \\
\hline
\end{tabular}




\begin{tabular}{|c|c|c|c|c|}
\hline Constructs & Sub-constructs & Items & Average & Ecart-types \\
\hline \multirow{14}{*}{ PERFORMANCE } & \multirow{9}{*}{ P-MARKETING } & MIT2 & 5,037 & 1,521 \\
\hline & & MIT3 & 5,088 & 1,792 \\
\hline & & MIT4 & 5,426 & 1,603 \\
\hline & & PMA1 & 5,118 & 1,306 \\
\hline & & PMA2 & 5,397 & 1,196 \\
\hline & & PAD1 & 4,478 & 1,766 \\
\hline & & PAD2 & 4,559 & 1,63 \\
\hline & & PAD3 & 4,515 & 1,59 \\
\hline & & PAD4 & 4,507 & 1,539 \\
\hline & \multirow[t]{5}{*}{ P-ADMIN } & PAD5 & 4,735 & 1,426 \\
\hline & & PAD6 & 4,985 & 1,254 \\
\hline & & PAD7 & 5,228 & 1,323 \\
\hline & & PAD8 & 5 & 1,419 \\
\hline & & PAD9 & 4,897 & 1,53 \\
\hline
\end{tabular}

Results of the internal model give in table 6 presents the hypothesis test. We note that only 02 out of 11 hypotheses have a tStudent below 1.96 by Hair et al. Hypotheses $\mathrm{H} 7$ and $\mathrm{H} 9$ are rejected while the others are accepted.

Table 6. Results of the hypotheses tests.

\begin{tabular}{llllll}
\hline & Hypothèses & Coefficients & t & p & Conclusion \\
\hline H4a & RM-CMM $\rightarrow$ SYSQUAL & 0,707 & 18,969 & 0,000 & Accepted \\
H4b & RM-CMM $\rightarrow$ SERVQUAL & 0,641 & 13,079 & 0,000 & Accepted \\
H5 & SERVQUAL $\rightarrow$ INFOQUAL & 0,574 & 5,826 & 0,000 & Accepted \\
H6 & SYSQUAL $\rightarrow$ INFOQUAL & 0,271 & 2,608 & 0,01 & Accepted \\
H7 & SYSQUAL $\rightarrow$ P-ADMIN & 0,600 & 3,869 & 0,000 & Accepted \\
H8 & RM-CMM $\rightarrow$ P-ADMIN & $-0,015$ & 0,195 & 0,845 & Accepted \\
H9 & SERVQUAL $\rightarrow$ P-ADMIN & 0,258 & 1,855 & 0,063 & Accepted \\
H10 & SERVQUAL $\rightarrow$ P-MARKETING & 0,622 & 12,674 & 0,000 & Accepted \\
H11 & RM-CMM $\rightarrow$ IT-INFRASTRUCTURE & 0,346 & 5,423 & 0,000 & Accepted \\
H12 & RM-CMM $\rightarrow$ IT-PERSONNEL & 0,363 & 4,765 & 0,000 & Accepted \\
H13 & RM-CMM $\rightarrow$ IT-MANAGEMENT & 0,594 & 9,723 & 0,000 & Accepted \\
\hline
\end{tabular}

The research model gives us the opportunity to test two mediation effects: System quality between RM-CMM and Administrative performance, and Service quality between RM-CMM and Administrative performance.
Following the Baron and Kenny and Sobel test (see Table 7), it appears that System quality has a complete and significant mediation effect between RM-CMM and Administrative performance.

Table 7. Test results of System quality mediation effect.

\begin{tabular}{lllll}
\hline Tests & Links & Coefficients & t & p \\
\hline Totaleffect & RM-CMM $\rightarrow$ P-ADMIN & 0,574 & 9,854 & 0,000 \\
H4a & RM-CMM $\rightarrow$ SYSQUAL & 0,707 & 18,969 & 0,000 \\
H7 & SYSQUAL $\rightarrow$ P-ADMIN & 0,600 & 3,869 & 0,000 \\
H8 & RM-CMM $\rightarrow$ P-ADMIN & $-0,015$ & 0,195 & 0,845 \\
\hline
\end{tabular}

Similarly, Service quality has not a mediation effect between RM-CMM and Administrative performance (see Table 8).

Table 8. Test results of Service quality mediation effect.

\begin{tabular}{lllll}
\hline Tests & Links & Coefficients & t & p \\
\hline Totaleffect & RM-CMM $\rightarrow$ P-ADMIN & 0,574 & 9,854 & 0,000 \\
H4b & RM-CMM $\rightarrow$ SERVQUAL & 0,641 & 13,079 & 0,000 \\
H9 & SERVQUAL $\rightarrow$ P-ADMIN & 0,258 & 1,855 & 0,063 \\
H8 & RM-CMM $\rightarrow$ P-ADMIN & $-0,015$ & 0,195 & 0,845 \\
\hline
\end{tabular}

\section{Discussions}

Using the Delone and McLean IS success model in the Cameroonian environment close to IT, IS and security professionals has enabled us to produce results that have implications both in social science research and in IS management.

This research brought evidence that ISMS have positive effects on IT capability (infrastructure, management quality and personnel skills) and performance (marketing and administrative) in enterprises. This research also permit to 
confirm moreover the significant positive effect of IT capability on firm performance [35-37].

Several authors have come to the conclusion that improving the security means taking into account the human factor and behavior, and improve the human resources qualities [38, 39]. This is confirmed with that the improvement of information security facilitates improving the quality of information security personnel, thus IT capability.

$50 \%$ of respondents are from the banking and telecommunications sectors, and are IS, IT and security consultants. In our environment, IS are already highly developed in the Banking and telecommunications sectors. Their vision of the ISMS importance in a company appears clearly in our findings. This means that any company should therefore invest on information security because it contributes to their performance.

\subsection{Results' Contribution}

Improving the maturity of information security risk management system implies continuously improvement of the risk management process as those of ISO 27005. This improvement suggests the mastery of risk management tools such as MEHARI. In an information security risk management process, once risks are identified, it needed to be treated. What makes reliable ISMS and increases its quality and its services.

Improving the maturity level of information security risk management system improves the IT capability of a company This result is not surprising because the change or improvement of IT capability is most noticeable in an enterprise during the information security risk management process. For example, in the risk management, ISMS will concentrate on the security services audit in order to determine the vulnerabilities of IS and at last make decision for delete this vulnerability. As part of an information security audit that we conducted in a company, we recommended training courses (ISO 27001 Lead Implementer certification) for the chief security officer as one of the objective of this company was to achieve an ISO 27001 certification as to reassure its customers in terms of their information security.

It is clear that improving the ISMS quality has a positive effect on improving the administrative performance. Indeed, the fact that the ISMS is reliable and delivers its activities on time is an advantage for the company's core business, in which it should therefore be executed on time. Likewise, more flexible is the ISMS, more the global management system is.

Improving the maturity level of information security risk management system helps but not directly improving administrative performance. In fact, we noticed that the System quality had a complete mediation effect between RM-CMM and Administrative performance. This means that concentrating on information security risk management without focusing on ISMS quality will not facilitate administrative performance. It will be important to focus on some quality indicators of any system such as reliability, flexibility, ease of use and functionality. This result is somehow surprising because supplier management is one of the elements of the administrative performance. Information security risk management calls us to emphasize on supplier management regarding contracts and services (content and form, on-time, name and reference products). It increases the firm's performance. In this sense, we have think improving maturity level of information security risk management directly improve administrative performance.

Information delivered by ISMS are assets in a company. As such, it is important that their quality is very good. This quality is guaranteed by the quality of the ISMS and the quality of services delivered by the ISMS. Indeed, a good ISMS guarantees compliance; which allows the goodness of the information's presentation. Good ISMS services quality helps employees to feel at ease and to be update.

When ISMS delivers good services, these are reliable and they meet the customers' needs and stakeholders' satisfaction. The direct net profit is the improvement of customer's satisfaction. Indeed, ISMS designs its services taking into consideration stakeholders' requirements. For example, customers want their data secured and the ISMS's services will encrypt them at any transaction. They will also recommend periodic passwords changing. All this contributes to customer satisfaction.

\subsection{Limits and Generalizations}

The first limitation of our study is at the level of performance measurement. We restricted our study on administrative and marketing performance because they are aspects with less interest in companies of our environment. This is not the case of financial performance which is the main indicator to measure performance in our environment. Then one might wonder if security allows a company to be financially efficient.

Secondly, our study was limited to the Cameroonian environment and especially to IS, IT and security professionals. Yet all employees are concerned by information security as far as they participate at different level in securing information assets.

The third limitation is the small size of our study sample although it was sufficient enough to produce acceptable results. The small size does not allow us to categorize analysis. It would have been interesting to know whether our hypotheses have the same significance in the bank or telecommunications sector, between operational employees and managers, people trained in information security or not, small or large company. This would have allowed us to make specific recommendations following each group.

Another limitation is the lack of precise detail on the significance of the relationship that may exist between IT capability and performance sub-constructs. Indeed, it would have been interesting to analyze the relationship between IT management, IT staff and administrative and marketing performance. Moreover, accurate analysis of the relationship between the maturity level of information security risks and 
suppliers' management would be much expressive.

These limits are some elements we can rely on to improve this research. For example, we can increase the sample size and observe the changes of results. It will also be interesting to analyze a particular category of respondents.

Our research draws attention to stakeholders on the performance measurement. Indeed, the performance of a company will no longer be financial. This remark draws our attention on the fact that we can therefore measure the performance of non-profit organization.

\section{Contributions}

This last section allows us to propose solutions for a better contribution of ISMS to the performance of a company.

\subsection{Managerial Implications}

The main recommendation is the implementation of an ISMS or the compliance with an existing ISMS, based on ISO 27001 standards. The findings showed the need to focus on the continuous improvement of the maturity level of information security risk management process. This improvement will facilitate a good quality of ISMS. This recommendation will involve global requirements at several levels of the company.

At the level of the directorate. It is mainly a question of managing policy issues and facilitating the implementation of ISMS. It is necessary to:

1. Lay the foundation for change management in the integration project of an ISMS.

2. Communicate constantly on net benefits of an ISMS in the company.

3. Give some flexibility to the security manager that could be related rather to the board of administration instead of the CEO or CIO. This will facilitate him collecting data for security needs and implementing different solutions.

4. Allow the information security manager to intervene in the choice and requirements of supplier's services and to propose content elements for the business insurance.

At the level of the chief information officer. Here, actors must manage and master the ISMS process and particularly the risk management according to the ISO 27005 standard, we recommend therefore:

1. Creating key positions for the ISMS such as information security manager, information security risks manager and ISMS auditor.

2. The information security manager will have a certification in information security management and or ISO 27001 Lead Implementer certifications: he must be able to measure the security return on invest and have relevant information for the contribution of the security to firm's performance.

3. The information security risks manager must have an ISO 27005 Risk Manager certification and master risks management tools such as MEHARI or EBIOS.

4. The auditor of ISMS must have a certification in information security audit and or ISO 27001 Lead Auditor certification.

5. The continuous training of those managers because it is important they update daily update their knowledge to adapt the security to the environment.

6. The IS department will formalize the ISMS process and have a security dashboard to accurately measure their activity and the achievement of objectives.

7. A communication plan should be developed to facilitate the acceptance and implementation of security measures.

At the level of the information security manager. Activities must be done daily and expenditures allocated for security needs justified. Generally, it plays a major role such as counselling, support, information, training and alert. It can intervene directly on all or part of the company's IS. Indeed, he must:

1. Master the various department of the company.

2. Master change management.

3. Manage the information security risk.

4. Develop solutions for information security problems.

5. Implement or monitor the implementation of these solutions.

6. Implement the business continuity plan.

7. Implement an information security dashboard.

8. Calculate the information security return on invest.

\subsection{Theoretical Implications}

In our research, we implemented the IS success model of Delone and McLean on ISMS. The maturity level of process is a quality management indicator of any system given that the quality management is based on process [40]. So we choose to use the maturity level of information security management process as a separate variable. We noted that the maturity level of process is very influential in an ISMS within a company. Can we not improve Delone and McLean IS success model concerning management systems? We will then have four (04) dependent variables: system quality, information quality, service quality and maturity Level of process.

\section{Conclusion}

Actually, the ISMS, which encompasses people, processes and IT systems, is the systemic approach whereby an organization ensures the security of information by a risk management process.

The main problem in Cameroon is the awareness of the setting up the management of information assets security of the enterprise because the losses are real, even if their frequency is negligible for some leaders who prefer curative methods.

The measurement of performance is critical for a company and for each of its departments. It is therefore important to determine the aspects that facilitate the measurement of the performance of the information security department and its contribution to the overall performance of the company. 
However, the resistance of the respondents did not facilitate our work. Otherwise, this could have improved our model. We could have better defined the concepts of administrative performance and marketing performance in total agreement with Cameroonian companies. This will permit the use of more meaningful manifest variables for decision makers to engage more quickly in the security of their information assets. This survey draws the attention of some managers on the importance of ISMS.

\section{References}

[1] Calder, A. and Watkins, S. G. (2007), Risk Assessment for Asset Owners, IT Governance Publishing, available at: http://www.jstor.org/stable/j.ctt5hh5xt.

[2] ISO/IEC. (2013), ISO 27001 Information Technology Security Techniques - Information Security Management Systems - Requirements.

[3] Calder, A. and Watkins, S. G. (2010), Information Security Risk Management for ISO27001/ISO27002, IT Governance Publishing, available at: http://www.jstor.org/stable/j.ctt5hh7jd

[4] Delone, W. H. and McLean, E. R. (1992), "Information Systems Success: The Quest for the Dependent Variable", Info. Sys. Research, Vol. 3 No. 1, pp. 60-95.

[5] Pitt, L. F., Watson, R. T. and Kavan, C. B. (1995), "Service Quality: A Measure of Information Systems Effectiveness", MIS Quarterly, Vol. 19 No. 2, pp. 173-187.

[6] Parasuraman, A., Zeithaml, V. and Berry, L. (1988), "SERVQUAL: A Multiple-Item Scale for Measuring Consumer Perceptions of Service Quality", Journal of Retailing, Vol. 64 No. 1, pp. 12-40.

[7] Wade, M. and Hulland, J. (2004), "Review: The ResourceBased View and Information Systems Research: Review, Extension, and Suggestions for Future Research", MIS Quarterly, Vol. 28 No. 1, pp. 107-142.

[8] Bharadwaj, A. S. (2000), “A Resource-Based Perspective on Information Technology Capability and Firm Performance: An Empirical Investigation", MIS Quarterly, Vol. 24 No. 1, pp. 169-196.

[9] Akter, S., FossoWamba, S., Gunasekaran, A., Dubey, R. and Childe, S. J. (2016), "How to improve firm performance using big data analytics capability?", International Journal of Production Economics.

[10] Teece, D. J., Pisano, G. and Shuen, A. (1997), "Dynamic capabilities and strategic management", Strategic Management Journal, Vol. 18 No. 7, pp. 509-533.

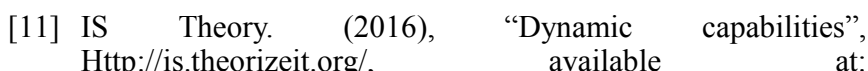
Http://is.theorizeit.org/, available at:
http://is.theorizeit.org/wiki/Dynamic_capabilities (accessed 20 April 2016).

[12] Urbach, N. and Müller, B. (2012), "The Updated DeLone and McLean Model of Information Systems Success".

[13] Gorla, N., Somers, T. M. and Wong, B. (2010), "Organizational impact of system quality, information quality, and service quality", J. Strateg. Inf. Syst., Vol. 19 No. 3, pp. 207-228.
[14] Ali, B. M. and Younes, B. (2013), The Impact of Information Systems on User Performance: An Exploratory Study.

[15] Lin, H.-Y., Hsu, P.-Y. and Ting, P.-H. (2006), "ERP Systems Success: An Integration of IS Success Model and Balanced Scorecard.”, Journal of Research and Practice in Information Technology, Vol. 38 No. 3, pp. 215-228.

[16] Marina Trkman and Peter Trkman. (2009), “A wiki as intranet: a critical analysis using the Delone and McLean model", Online Information Review, Vol. 33 No. 6, pp. $1087-1102$.

[17] Sedera, D., Tan, F. and Dey, S. (2007), "Identifying and Evaluating the Importance of Multiple Stakeholders Perspective in Measuring ES-Success", European Conference on Information Systems, Association of Information Systems AIS, Gothenburg Sweden, available at: http://eprints.qut.edu.au/10288/.

[18] Bharati, P. and Chaudhary, A. (2006), "Product Customization on the Web: An Empirical Study of Factors Impacting Choiceboard User Satisfaction", Inf. Resour. Manage. J., Vol. 19 No. 2, pp. 69-81.

[19] Kulkarni, U. R., Ravindran, S. and Freeze, R. (2006), “A Knowledge Management Success Model: Theoretical Development and Empirical Validation", Journal of Management Information Systems, Vol. 23 No. 3, pp. 309347.

[20] Bradley, R. V., Pridmore, J. L. and Byrd, T. A. (2006), "Information Systems Success in the Context of Different Corporate Cultural Types: An Empirical Investigation", Journal of Management Information Systems, Vol. 23 No. 2, pp. 267-294.

[21] Arsanjani, A., Bharade, N., Borgenstrand, M., Schume, P., Wood, J. K. and Zheltonogov, V. (2015), Business Process Management Design Guide Using IBM Business Process Manager, edited by (Firm), S. B. O. and Organization, I. B. M. C. I. T. S., First edition., IBM Corporation, International Technical Support Organization, Poughkeepsie, NY, available at: https://briagg.rbc.edu/login?url=http://proquest.safaribooksonl ine.com/?uiCode $=$ cwm\&xmlId $=9780738440590$.

[22] Ray, D., Haon, C. and Gotteland, D. (2001), "Effets médiateurs et modérateurs au sein de la relation satisfaction - fidélité : vers une meilleure compréhension du rôle de l'image".

[23] Faris, S., Iguer, H., Medromi, H. and Sayouti, A. (2013), "Conception d'une Plateforme de gestion des risques basée sur les systèmes multi-agents et ISO 27005".

[24] Anand, A. (2013), The Effect of IT Capabilities on Firm Performance - Evidence from Healtcare Industry, Master of Information Systems and Technology - Research thesis, School of Information Systems \& Technology, University of Wollongong.

[25] Mithas, S., Ramasubbu, N., Krishnan, M. S. and Sambamurthy, V. (2004), "Information Technology Infrastructure Capability and Firm Performance: An Empirical Analysis".

[26] Yin, R. (2011), "Case study research: Design and methods (4th Ed.)", SAGE Publication.

[27] Hair, joseph, Hult, T., Ringle, C. and Sarstedt, M. (2014), A Primer on Partial Least Squares Structural Equation Modeling (Pls-Sem). 
[28] Henseler, J., Ringle, C. and Sarstedt, M. (2014), "A new criterion for assessing discriminant validity in variance-based structural equation modeling", Springerlink.com.

[29] Nunnaly and Bernstein. (1994), "Psychometric Theory, 3th edition”, McGraw-Hil, New York.

[30] Baron, R. M. and Kenny, D. A. (1986), "The ModeratorMediator variable distinction in Social Psychological research: Conceptual, strategic, and statistical considerations", Journal of Personality and Social Psychology.

[31] Nitzl, C., Roldan, J. and Carrion, G. C. (2016), "Mediation Analysis in Partial Least Squares Path Modeling: Helping Researchers Discuss More Sophisticated Models", Social Science Research Network, available at: http://papers.ssrn.com/sol3/papers.cfm?abstract_id=2789370.

[32] Preacher, K. J. and Hayes, A. F. (2008), "Asymptotic and resampling strategies for assessing and comparing indirect effects in multiple mediator models", Behavior Research Methods, Vol. 40 No. 3, pp. 879-891.

[33] Sobel, M. E. (1982), “Asymptotic Confidence Intervals for Indirect Effects in Structural Equation Models", Sociological Methodology, Vol. 13, pp. 290-312.
[34] Bhattacherjee, A. (2012), "Social Science Research: Principles, Methods, and Practices", Textbooks Collection, Book 3.

[35] Addas, S. and Pinsonneault, A. (2007), "IT capabilities and firm performance: A resource-based, alliance perspective", Desautels Faculty of Management. McGill University.

[36] Iansiti, M. and Favaloro, G. (2006), Enterprise IT Capabilities and Business Performance. Harvard Business School, Keystone Strategy Inc.

[37] Lazic, M. (2011), "IT Governance and Business Performance A Resource Based Analysis", PACIS 2011 Proceedings. Paper 103, available at: http://aisel.aisnet.org/pacis2011/103.

[38] Ashenden, D. (2008), "Information Security management: A human challenge?" Information Security Technical Report, Vol. 13 No. 4, pp. 195-201.

[39] Crossler, R. E., Johnston, A. C., Lowry, P. B., Hu, Q., Warkentin, M. and Baskerville, R. (2013), "Future directions for behavioral information security research", Computers \& Security, Vol. 32, pp. 90-101.

[40] Software Engineering Institute. (2010), CMMI ${ }^{\circledR}$ for Development, Version 1.3, available at: http://www.sei.cmu.edu.

[41] Bender, O. (2008), Introduction À La Fidélisation En Entreprise. 